\title{
Surgical revascularization of hibernating myocardium: the known and the unknown
}

\author{
Arnaldo Dimagli, Umberto Benedetto \\ Bristol Heart Institute, University of Bristol, Bristol BS2 8HW, UK.
}

Correspondence to: Dr. Umberto Benedetto, MD, PhD, Bristol Heart Institute, University of Bristol, Office Room 84, Level 7, Bristol Royal Infirmary, Upper Maudlin Street, Bristol BS2 8HW, UK.E-mail: umberto.benedetto@bristol.ac.uk

How to cite this article: Dimagli A, Benedetto U. Surgical revascularization of hibernating myocardium: the known and the unknown. Vessel Plus 2021;5:13. http://dx.doi.org/10.20517/2574-1209.2020.91

Received: 14 Dec 2020 First Decision: 5 Jan 2021 Revised: 14 Jan 2021 Accepted: 18 Jan 2021 Published: 12 Mar 2021

Academic Editor: Shahzad G. Raja Copy Editor: Xi-Jun Chen Production Editor: Yue-Yue Zhang

\begin{abstract}
Coronary artery disease (CAD) represents the leading cause of chronic heart failure in developed countries. Ischemic heart failure is mainly characterized by impairment of left ventricle systolic function which can result from scarring of myocardium after myocardial infarction, stunning myocardium and hibernating myocardium. Hibernating myocardium represents a cause of ischemic left ventricular dysfunction amenable to recovery after revascularization. Several viability imaging modalities are available but their role in the clinical decision-making process and the prognostic value of viability in patients undergoing revascularization are still debated. When available, cardiac magnetic resonance or positron emission tomography should be preferred over the others as they show higher performance in terms of sensitivity and higher spatial resolution. Several observational studies have supported a positive prognostic value to the presence of viable myocardium for patients undergoing revascularization. This was not confirmed in randomized clinical trials. This lack of evidence does not support a precise role of viability assessment in the clinical decision-making process, and therefore, myocardial viability should be only one of the several factors considered in the clinical decision-making process.
\end{abstract}

Keywords: Hibernating myocardium, viability imaging, surgical revascularization

\section{INTRODUCTION}

Coronary artery disease (CAD) represents the leading cause of chronic heart failure in developed countries $^{[1]}$ with currently 18.2 million Americans ${ }^{[2]}$ and 126 million individuals worldwide suffering from

(C) The Author(s) 2021. Open Access This article is licensed under a Creative Commons Attribution 4.0 International License (https://creativecommons.org/licenses/by/4.0/), which permits unrestricted use, sharing, adaptation, distribution and reproduction in any medium or format, for any purpose, even commercially, as long as you give appropriate credit to the original author(s) and the source, provide a link to the Creative Commons license, and indicate if changes were made.

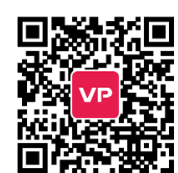


ischemic heart disease (IHD $)^{[3]}$. One of the clinical sequelae of IHD is ischemic heart failure, which is associated with a high burden of morbidities and an increased risk of mortality. Ischemic heart failure is mainly characterized by impairment of left ventricle systolic function, which can result from scarring of myocardium after myocardial infarction, stunning myocardium and hibernating myocardium. Although the last is characterized by a complete loss of viable cardiomyocytes, which are replaced by fibrous tissue, the first two conditions are characterized by preserved myocardial viability and metabolic and structural adaptation of cardiomyocytes to ischemia.

Hibernating myocardium represents an adaptive status characterized by a persistently reduced myocardial contractility as a result of repetitive myocardial ischemia events in the context of a chronically reduced myocardial blood flow and reduced coronary reserve. This translates into left ventricle dysfunction at rest $^{[4]}$. Due to the presence of viable myocardium, revascularization of these hibernating areas has always been an attractive strategy to recover ventricular function and therefore improve survival.

Evidence arising from observational studies regarding revascularization in patients with ischemic heart failure was contentious for many years ${ }^{[5-8]}$ until the 10-year outcomes of the Surgical Treatment for Ischemic Heart Failure (STICH) trial confirmed a significant benefit in cardiovascular mortality for patients undergoing coronary artery bypass grafting (CABG) plus optimal medical therapy compared to those receiving optimal medical therapy only ${ }^{[9]}$. However, the role of viability assessment still remains uncertain as the STICH trial showed that the presence of viable myocardium was not a predictor of better outcomes after CABG. Hence, the role of myocardium viability assessment in clinical decision-making is still debated and controversial.

\section{PATHOPHYSIOLOGY}

The first description of hibernating myocardium was given by Rahimtoola ${ }^{[10]}$ in 1989 and identified this as an adaptive downregulation of contractile function as a result of myocardial ischemia, so that myocardial oxygen demand is balanced with coronary blood supply and that necrosis of myocytes is prevented. This means that there is a perfusion-contraction matching as opposed to stunning myocardium, where there is a perfusion-contraction mismatch as myocardial contractility remains impaired after a transient episode of ischemia $^{[11]}$.

The reduction in coronary flow reserve represents the main mechanism for the induction of hibernation in patients with CAD. This determines a rearrangement of the metabolism and of the structural organization of the cardiomyocytes, leading to a reduction in contractility and therefore to perfusion-contraction matching. The reduced supply of oxygen and nutrients from blood translates into energy depletion with progressively reduced levels of ATP. This depletion is partly attenuated by an increased drift towards anaerobic glycolysis, which prevents the further destruction of cardiomyocytes. Accordingly, an increased uptake of glucose and a higher number of glucose transporter proteins on the sarcolemma have been described and are currently exploited in some diagnostic imaging modalities. Also, cytosolic granules of glycogen are more abundant in hibernating myocardium to maintain the glycolytic pathway ${ }^{[12]}$.

This metabolic adaptation is able to hinder cell damage and necrosis. Besides, major structural changes have been demonstrated in the hibernating myocardium. The reduction in the contractility function is characterized by a modification in the translational programs of these cardiomyocytes with a neat reduction in myofilaments and cytoskeleton proteins. In particular, studies have shown a reduction in titin and $\alpha$-actinin, which leads to structural disorganization of myocytes and therefore sarcomere instability. Also, loss of the sarcoplasmic reticulum and degeneration of mitochondria are present. These changes result in shrinking and atrophy of the cardiomyocytes and activation of the repair mechanisms, which, at last, determine the development of interstitial fibrosis ${ }^{[13,14]}$. 
Table 1. Characteristics of the available imaging modalities to assess myocardial viability

\begin{tabular}{|c|c|c|c|}
\hline Imaging modality & Advantages & Disadvantages & Diagnostic performance \\
\hline Echocardiography & $\begin{array}{l}\text { Widely available and } \\
\text { readily-available } \\
\text { Inexpensive }\end{array}$ & $\begin{array}{l}\text { Operator-dependent } \\
\text { Limited resolution in } \\
\text { patients with lung disease } \\
\text { or obesity }\end{array}$ & $\begin{array}{l}\text { Dobutamine stress } \\
\text { echocardiography: } \\
\text { Sensitivity } 80 \% \\
\text { Specificity } 78 \%\end{array}$ \\
\hline Cardiac magnetic resonance & $\begin{array}{l}\text { Highly reproducible } \\
\text { Excellent spatial } \\
\text { imaging } \\
\text { Accurate } \\
\text { quantification of } \\
\text { nonviable myocardium }\end{array}$ & $\begin{array}{l}\text { Less accessible } \\
\text { Costs } \\
\text { Unstable patients or } \\
\text { patients with implantable } \\
\text { devices may not be eligible }\end{array}$ & $\begin{array}{l}\text { Late gadolinium } \\
\text { enhancement: } \\
\text { Sensitivity } 95 \% \\
\text { Specificity 51\% }\end{array}$ \\
\hline $\begin{array}{l}\text { Single-photon emission } \\
\text { tomography }\end{array}$ & $\begin{array}{l}\text { Widely available } \\
\text { Easy to perform } \\
\text { Reproducible }\end{array}$ & $\begin{array}{l}\text { Low spatial resolution } \\
\text { Costs } \\
\text { Radiation exposure } \\
\text { Attenuation artefacts }\end{array}$ & $\begin{array}{l}\text { Sensitivity } 81-86 \% \\
\text { Specificity } 59-66 \%\end{array}$ \\
\hline $\begin{array}{l}\text { Positron emission } \\
\text { tomography }\end{array}$ & High spatial resolution & $\begin{array}{l}\text { Costs } \\
\text { Not widely available }\end{array}$ & $\begin{array}{l}\text { Sensitivity 93\% } \\
\text { Specificity 53\% }\end{array}$ \\
\hline
\end{tabular}

\section{IMAGING}

Different imaging techniques have been used to investigate the presence and the extent of hibernating myocardium in patients with CAD. The main aim of these imaging modalities is to assess the presence of viable myocardium and study the structural and functional integrity of cardiomyocytes. The principal limit of these diagnostic procedures is that a definitive diagnosis of hibernating myocardium can only be made retrospectively, after having assessed a proper functional recovery of imaging-detected hypo-contractile regions following revascularization. Therefore, the performance of these assessments to prospectively identify viable tissue as hibernating myocardium remains variable in terms of sensitivity and specific, and systematic application in the clinical decision-making process is still not present [Table 1].

The different pathophysiological aspects that characterize hibernating myocardium, such as metabolic changes or tissue scarring, are specifically targeted by these diagnostic modalities.

Echocardiography represents a widespread, readily-available and inexpensive diagnostic tool able to provide information on the left ventricle contractile function. There are three echocardiographic applications: at rest echocardiography, dobutamine stress echocardiography (DSE) and contrast echocardiography. At rest, evaluation of left ventricle is able to inform on left ventricle ejection fraction (LVEF) and wall motion abnormalities, indicating the presence of areas of a-, hypo- or dyskinesia. Moreover, it allows measurements of wall thickness. In particular, the presence of an end-diastolic wall thickness less than 6 $\mathrm{mm}$ has been demonstrated to predict areas of myocardium which will not recover after revascularization, whereas segments with a thickness more than $8 \mathrm{~mm}$ accurately diagnoses areas that are able to recover after revascularization ( $94 \%$ sensitivity and $48 \%$ specificity $)^{[15]}$. On the other hand, DSE provides insights regarding the contractile reserve of myocardium under inotropic stimulation. The presence of hibernating myocardium is typically characterized by an initial improvement phase after infusion of low-dose dobutamine $(5-10 \mu \mathrm{g} / \mathrm{kg} / \mathrm{min})$, followed by a deterioration phase as dobutamine dose is increased $(10-40 \mu \mathrm{g} / \mathrm{kg} / \mathrm{min})$. This is due to the impossibility of coronary blood flow to match tissue oxygen demand when the inotropic load increases. This phenomenon has been shown to be highly predictive of functional recovery after revascularization ${ }^{[16]}$. Stress echocardiography has a sensitivity of $80 \%$ and a specificity of $78 \%$ with a positive predictive value of $75 \%$ and negative predictive value of $83 \%{ }^{[17]}$ in identifying segments able to recover after revascularization. Finally, contrast echocardiography uses the infusion of microbubbles of encapsulated high-molecular-weight gas, and it is able to provide images reflective of myocardial blood flow. The performance of this procedure is characterized by high sensitivity and low specificity, and therefore, if combined with DSE, it is able to ensure an optimal prediction tool of successful recovery after revascularization (96\% sensitivity, $63 \%$ specificity $)^{[18]}$. The major limitation of echocardiography is related to the sonographic window of each patient, since patients with chronic lung disease or obesity may have a 
worst resolution of the imaging, and the operator-dependence, which makes it less reproducible than other imaging modalities.

Recently, speckle-tracking echocardiography has emerged as an accurate tool to assess regional myocardial deformation, in terms of strain and strain rate ${ }^{[19]}$. Strain represents the deformation of myocardium and strain rate is the gradient of the velocities of this deformation. This technique is able to detect subtle wall motion abnormalities. In particular, a reduction in circumferential strain has been shown to be a strong predictor of nonviable myocardium, whereas longitudinal strain is able to distinguish between viable and nonviable tissue with a sensitivity of $81 \%^{[20]}$. One advantage of speckle-tracking echocardiography is its minor operator-dependence compared to two-dimensional echocardiography.

Cardiac magnetic resonance (CMR) is another diagnostic tool used to identify hibernating myocardium with the ability to assess contractile reserve, wall thickness and tissue scarring. This procedure is highly reproducible and provides excellent spatial imaging. Tissue scarring is visualized through late-gadolinium enhancement which represents the gold standard for assessment of myocardial scar. Ten minutes after the intravenous infusion of gadolinium, normal myocardium will appear black whereas myocardial scar, representing nonviable tissue, is bright. It has been shown that the transmural extent of the scar is inversely correlated with the probability of recovery of contractile function after revascularization ${ }^{[21]}$. In particular, a threshold of $50 \%$ transmurality is able to predict functional myocardial recovery with a sensitivity of $95 \%$ and a specificity of $51 \%{ }^{[22]}$. Late-gadolinium enhancement can be complemented by assessment of extracellular volume fraction, which reflects the size of the extracellular space and can be measured based on native and post-contrast $\mathrm{T} 1$ images. Recent studies supported a potential role of this technique to improve the prediction of segmental and global functional myocardial recovery ${ }^{[23,24]}$. A new technique based on feature-tracking CMR, which is conceptually similar to speckle-tracking echocardiography, has proven that CMR-assessed regional and longitudinal strains are able to identify areas of myocardial scarring detected by late-gadolinium enhancement. This technique can potentially forego the need of contrastbased CMR with the benefits of shorter scan time and of alleviating concerns regarding the deposits of gadolinium in tissues ${ }^{[25]}$.

Contractile reserve is assessed by low-dose dobutamine $(5-10 \mu \mathrm{g} / \mathrm{kg} / \mathrm{min})$ stress CMR and evaluation of left ventricle wall thickness. An increase of 2 or more $\mathrm{mm}$ in systolic thickening is considered a sign of viability within the considered myocardial segment ${ }^{[26]}$. This methodology has a sensitivity of $81 \%$ and specificity of $91 \%$, and therefore, the combination of the high specificity of low-dose dobutamine CMR with the high sensitivity of late-gadolinium enhancement leads to an optimal accuracy in identifying viable myocardium $^{[22]}$. Lastly, CMR can also measure at rest end-diastolic wall thickness and identify areas of scarring as those in which the ventricle wall is less thick than $6 \mathrm{~mm}$ (96\% sensitivity and $38 \%$ specificity $)^{[22]}$. The use of CMR is mainly limited by being less accessible compared to echocardiography, and therefore, its systematic introduction in the clinical decision-making process may be difficult. Moreover, unstable patients and patients with implantable devices (e.g., pacemaker) may not be eligible to undergo magnetic resonance.

Single-photon emission computed tomography (SPECT) is a nuclear imaging technique able to study the integrity of cardiomyocytes by means of radiotracers. 201Thallium and 99mTc-sestamibi are the most common used radiotracers: the former requires preserved functioning of mitochondria and the latter will be retained in cardiomyocytes with intact sarcolemma. Hence, both of them are able to identify viable myocardium. Systolic function can be evaluated at rest or after physical exertion or infusion of dipyridamole/adenosine. Myocardial viability is identified by myocardial segments with defective uptake of the radiotracer. To recognize segments still viable but critically hypoperfused, a 24-h imaging cycle should be performed to guarantee time for tracer redistribution within these segments ${ }^{[27]}$. The sensitivity 
of SPECT is $81 \%-86 \%$ and its specificity is $59 \%-66 \%$. The main factor impacting this performance is the low spatial resolution. In fact, when compared to late-gadolinium CMR, the likelihood of SPECT detecting viable myocardium increases with increasing transmural extent. Only half of nonviable segments identified by late-gadolinium enhancement and with involvement of less than $50 \%$ of wall thickness, were detected by SPECT ${ }^{[28]}$. Other disadvantages of this imaging modality include costs, patient exposure to ionizing radiation and attenuation artefacts.

Positron emission tomography is another nuclear imaging modality which allows the assessment of both myocardial perfusion and metabolism. The standardly used radiotracers are $13 \mathrm{~N}$-labeled ammonia $(13 \mathrm{NH} 3)$ and $18 \mathrm{~F}$-fluorodeoxyglucose $(18 \mathrm{FDG})$ for perfusion and metabolic activity, respectively. Myocardial segments are assessed in terms of perfusion-metabolism matching. As discussed in the pathophysiology section, hibernating myocardium is characterized by an increased uptake of glucose driven by a drastic shift towards anaerobic glycolysis. Hence, hibernating myocardium will be characterized by perfusion-metabolism mismatch, with perfusion being reduced and glucose uptake increased. Nonviable myocardium is characterized by a perfusion-metabolism match as both blood flow and glucose uptake are decreased. One drawback of this metabolic assessment is that glucose uptake may be influenced by several factors, such as glycemic status, sympathetic activation and, fasting duration. Having a high spatial resolution, PET has the highest sensitivity to detect tissue viability (93\%) and is therefore considered the gold standard for this assessment. However, its sensitivity for detection of contractile reserve remains ${ }{ }^{\left[0{ }^{[29]}\right.}$. Similar to SPECT, PET use is mostly limited by its associated costs which limit a widespread availability. More recently, Madsen et al. ${ }^{[30]}$ highlighted the importance of the center volume of patients undergoing PET as a keystone to maintain the expertise regarding preparation protocols, processing of PET images, interpreting the perfusion/metabolism maps and relaying conclusions.

Definitively, there are numerous imaging modalities that can be used to identify viable, hypoperfused myocardium. Each of them is characterized by a peculiar performance in terms of sensitivity and specificity, and therefore, one can be preferred over another to identify patients who will successfully recover myocardial function. Factors influencing this choice may concern the local availability of resources, the local expertise and the clinical settings.

Current guidelines do not recommend one modality over the others but recommend noninvasive imaging testing for myocardial viability in patients with CAD and reduced LVEF or abnormal wall motion, who are being considered for revascularization ${ }^{[31]}$. CMR and PET are able to provide high spatial resolution and therefore increased sensitivity and should be preferred when available.

\section{REVASCULARIZATION OF VIABLE MYOCARDIUM}

Hibernating myocardium represents an adaptive status readily identifiable as viable myocardium by means of the different imaging techniques, but its prognostic outcome in case of revascularization is still debated. If revascularization of nonviable myocardium, such as scarring, is intuitively not able to improve the patient's prognosis, the impact of revascularization of hibernating segments has not been definitely established yet.

Numerous retrospective studies tried to address this question; however, their results always suffered from a retrospective design and incomplete control of confounding factors. In 2002, Allman et al. ${ }^{[5]}$ conducted a metanalysis including 24 studies comparing late survival in patients with CAD and left ventricle dysfunction undergoing revascularization $v s$. patients receiving medical therapy after myocardial viability testing (DSE, PET, SPECT). The analysis included 3088 patients with a mean age of 61 years and a mean LVEF of $32 \%$ and showed that revascularization granted a $76 \%$ reduction of annual mortality compared to medical therapy (3.2\% vs. $16 \%$ ). Interestingly, evidence of myocardial viability was directly associated with 
Table 2. The three randomized clinical trials concerning hibernating myocardium

\begin{tabular}{|c|c|c|c|c|c|}
\hline Study & $\begin{array}{c}\text { Number } \\
\text { of } \\
\text { patients }\end{array}$ & $\begin{array}{l}\text { Latest } \\
\text { follow- } \\
\text { up }\end{array}$ & $\begin{array}{c}\text { Viability } \\
\text { assessment } \\
\text { modality }\end{array}$ & Findings & Limitations \\
\hline $\begin{array}{l}\text { PET and recovery } \\
\text { following } \\
\text { revascularization } \\
\text { (PARR-2) }\end{array}$ & 430 & 5 years & $\begin{array}{l}\text { F-18 } \\
\text { fluorodeoxyglucose } \\
\text { PET }\end{array}$ & $\begin{array}{l}\text { No difference was found } \\
\text { between the FDG-PET arm } \\
\text { and the standard care arm } \\
\text { in terms of cardiac death, } \\
\text { myocardial infarction and } \\
\text { recurrent hospitalization, } \\
\text { but patients following FDG- } \\
\text { PET-recommendations were } \\
\text { found to have a significant } \\
\text { reduction in the composite } \\
\text { endpoint }\end{array}$ & $\begin{array}{l}\text { Poor adherence to the PET-based } \\
\text { recommendations }(74.5 \%) \\
\text { Lower-than-expected rates of outcomes of } \\
\text { interest } \\
\text { Pre-existing viability imaging tests in the } \\
\text { standard care arm }(65 \%) \\
\text { e }\end{array}$ \\
\hline $\begin{array}{l}\text { Heart Failure } \\
\text { Revascularization } \\
\text { Trial (HEART) }\end{array}$ & 138 & 5 years & $\begin{array}{l}\text { Any imaging } \\
\text { tool available } \\
\text { (more frequently } \\
\text { dobutamine stress } \\
\text { echocardiography) }\end{array}$ & $\begin{array}{l}\text { The study was not able } \\
\text { to show a superiority of } \\
\text { angiography followed by } \\
\text { revascularization compared } \\
\text { to conservative medical } \\
\text { therapy in these patients }\end{array}$ & $\begin{array}{l}\text { Small sample size (recruitment stopped earlier } \\
\text { than expected) } \\
\text { A third of patients assigned to the angiography } \\
\text { arm did not undergo revascularization } \\
\text { Dobutamine stress echocardiography had poorer } \\
\text { diagnostic performance compared to other } \\
\text { imaging modalities (i.e., PET) }\end{array}$ \\
\hline $\begin{array}{l}\text { Viability sub- } \\
\text { study of } \\
\text { the Surgical } \\
\text { Treatment for } \\
\text { Ischemic Heart } \\
\text { Failure (STICH) } \\
\text { trial }\end{array}$ & 601 & 5 years & $\begin{array}{l}\text { Dobutamine stress } \\
\text { echocardiography, } \\
\text { Single-photon } \\
\text { emission tomography }\end{array}$ & $\begin{array}{l}\text { The rate of all-cause } \\
\text { mortality did not differ } \\
\text { between patients with } \\
\text { viable vs nonviable } \\
\text { myocardium } \\
\text { In patients with viability, } \\
\text { CABG did not provide } \\
\text { survival benefit compared } \\
\text { to medical therapy alone }\end{array}$ & $\begin{array}{l}\text { Non-randomized, non-blinded design } \\
\text { Underpowered analysis with only } 60 \text { patients } \\
\text { without viability undergoing revascularization } \\
\text { Viability assessment was not standardized and } \\
\text { relied upon dobutamine stress echocardiography } \\
\text { and single-photon emission tomography while } \\
\text { more sensitive modalities are available } \\
\text { Differences in baseline characteristics between } \\
\text { the two groups } \\
\text { Possible selection bias as } 25 \% \text { of patients } \\
\text { undergoing viability assessment had mild } \\
\text { coronary artery disease. } \\
\text { 17\% assigned to medical therapy underwent } \\
\text { surgical revascularization }\end{array}$ \\
\hline
\end{tabular}

CABG: Coronary artery bypass grafting.

improved survival, whereas absence of viability did not show any benefit of revascularization and there was actually a trend towards a higher mortality. None of the imagining techniques investigated performed significantly better than the others in predicting the survival benefit after revascularization. The main limitations of this metanalysis were the observational nature of all the studies included and the lack of a homogenously defined and guideline-oriented optimal medical therapy ${ }^{[5]}$.

More sound evidence has been provided by three randomized trials [Table 2].

The PET and Recovery Following Revascularization (PARR-2) trial investigated the role of 18FDG-PET as viability testing in the management of 430 patients with suspected CAD and severe left ventricular dysfunction being considered for revascularization or transplantation ${ }^{[32]}$. Patients were randomized to standard care or PET-assisted management. At the first year of follow-up, the hazard ratio for the composite endpoint of cardiac death, myocardial infarction and recurrent hospital stay was 0.78 (95\%CI: 0.58-1.10). In the PET-assisted arm the cumulative proportion of patients experiencing the composite outcome was 30 vs. $36 \%$ in the standard care arm, leading to a relative risk of 0.82 (95\%CI: 0.59-1.14). Interestingly, patients in the PET arm who had undergone other previous viability tests were found to have a lower risk of the composite endpoint compared to patients in the standard care group with previous testing as well (HR 0.46, 95\%CI: 0.25-0.81). In a pre-specified post-hoc analysis, patients adhering to PET recommendations were less likely to experience the composite endpoint compared to patients managed with standard care (HR 0.62; 95\%CI: 0.42-0.93). The five-year results confirmed these finding ${ }^{[33]}$. No difference was found between the PET arm and the standard care arm in terms of cardiac death, myocardial infarction and recurrent hospitalization, but patients following PET-based recommendations were again confirmed to 
have a significant reduction in the composite endpoint (HR 0.73, 95\%CI: 0.54-0.94). This highlighted that the benefit of PET viability imaging is best achieved when adherence to imaging-based recommendations is likely.

The Ottawa-FIVE study was a post-hoc analysis of the PARR-2 trial which tested the hypothesis that PETassisted management can improve clinical benefit outcomes in patients with left ventricular dysfunction and suspected CAD compared to patients managed with standard care in a center with ready access to PET, imaging expertise and multidisciplinary teams ${ }^{[34]}$. A significant reduction in the composite endpoint of cardiac death, myocardial infarction and recurrent hospitalization was found in patients undergoing PET (HR 0.34, 95\%CI: 0.16-0.72). This study highlighted the importance of synergies between imaging, heart failure and revascularization expertise, in addition to the ready access to PET.

The main limitation of the PARR-2 study was the poor adherence to therapeutic strategy as only $75.4 \%$ of patients were treated consistently with the PET-based recommendations. Indeed, $14.5 \%$ of patients with high or moderate viability did not undergo revascularization. This reduced the power of the study, which was also jeopardized by lower-than-expected rates of outcomes. Also, the pre-existing imaging tests in the standard care arm (65\%) may have enhanced a crossover effect and lowered the benefit associated with viability imaging.

The Heart Failure Revascularization Trial (HEART) was meant to compare the all-cause mortality in patients with heart failure, $\mathrm{LVEF}<35 \%$ and evidence of myocardial viability by means of any imaging tool available receiving optimal medical treatment compared to patients undergoing angiography with the final aim of revascularization ${ }^{[35]}$. Due to slow recruitment, funding for the trial was withdrawn, and the final study sample consisted of 138 patients out of 800 planned to be included. 69 patients were randomized to invasive strategy, but only 45 had revascularization, and the most commonly adopted imaging testing was DSE. Over a 5 -year follow-up, $37 \%$ of patients in the conservative arm and $38 \%$ in the invasive strategy arm died. Therefore, the study was not able to show a superiority of invasive management compared to conservative medical therapy in these patients. However, these results must take into account the smaller sample size recruited than the expected one leading to an overall underpowered study. Moreover, about $35 \%$ of patients assigned to the angiography arm did not undergo revascularization, and finally, DSE was frequently used although its performance is characterized by a lower sensitivity in detecting viability compared to other imaging modalities.

The Surgical Treatment for Ischemic Heart Failure (STICH) trial investigated the role of coronary artery bypass grafting (CABG) in 1212 patients with CAD and left ventricular dysfunction (LVEF < 35\%) compared to the use of medical therapy alone with ACE inhibitors, beta-blockers, statins and diuretics ${ }^{[36]}$. The primary outcome was death from any cause and occurred in $36 \%$ of patients in the CABG group and $41 \%$ in the medical therapy group (HR $0.86,95 \% \mathrm{CI}: 0.72-1.04$ ). Only the 10-year follow-up study of the STICH trial could finally confirm a significant benefit in cardiovascular mortality in patients treated with CABG and medical therapy compared to patients receiving medical therapy alone (HR 0.79, 95\% CI: 0.66$0.93)^{[9]}$.

Regarding myocardial viability, a sub-study of the STICH trial reported on 601 patients undergoing imaging testing with DES, SPECT or both ${ }^{[37]}$. Myocardial viability was present in $81 \%$ of patients, and the rate of the primary outcome did not differ between patients with viable vs nonviable myocardium. Similarly, patients with myocardial viability did not have lower rates of cardiovascular death, but there was a lower rate of the composite endpoint of cardiovascular death and hospitalization. In patients with viability, CABG did not provide survival benefit compared to medical therapy alone. Therefore, this substudy failed to demonstrate a survival benefit for patients in which viability was proved and viability 
assessment was not able to recognize patients who would benefit from CABG relative to medical therapy alone. The main limitation of this sub-study was its non-randomized and non-blinded design. Second, the analysis was importantly underpowered as only 60 patients without viability underwent CABG. Third, viability assessment was not standardized and relied upon only DSE and SPECT whereas other more sensitive tests were not used (i.e., CMR). Fourth, patients undergoing viability assessment were more severely ill, with lower LVEF and higher left ventricular dilatation indices, suggesting a higher burden of ventricular remodeling. Furthermore, about $25 \%$ of the patients undergoing viability assessment had one vessel coronary artery disease, suggesting a selection bias including patients who would not be expected to benefit from revascularization. Finally, there was substantial crossover as $17 \%$ of patients assigned to medical therapy alone underwent CABG.

In view of these flaws in the sub-study, which may have introduced relevant biases, the results have to be interpreted critically.

The results of these randomized clinical trials have not supported what previous observational studies had shown. This discrepancy is likely due to a selection bias in observational studies in which patients with a higher burden of comorbidities (older patients, more complex coronary artery disease, more impaired LVEF) and shorter expected survival may have been denied surgical revascularization.

Hence, the prognostic role of revascularization in patients with viable myocardium still remains unclear and so is the usefulness of viability testing as a management tool for whether to go forward with revascularization procedures ${ }^{[38]}$.

Further insights may be provided by the Alternative Imaging Modalities in Ischemic Heart Failure (AIMIHF) study ${ }^{[39]}$. This trial will enroll patients with LVEF $<45 \%$ and suspected or known CAD who will be randomized to either standard imaging modalities (SPECT) for ischemia and viability or advanced imaging modalities, such as CMR or PET, and will undergo clinical management guided by these imaging testing methods. The primary endpoint of the study will be a composite of cardiac death, myocardial infarction, resuscitated cardiac arrest and cardiac rehospitalization.

\section{LIMITATIONS}

This study represents a narrative review and is not based on a systematic search of the existing literature, and therefore, there may be a bias regarding included studies and the conclusions drawn.

\section{CONCLUSION}

Hibernating myocardium represents a cause of ischemic left ventricular dysfunction amenable to recovery after revascularization. Several imaging modalities are able to identify viable myocardium, but whenever available CMR or PET should be preferred over the others for their higher performance in terms of sensitivity and higher spatial resolution.

Although observational studies have supported a positive prognostic value to the presence of viable myocardium for patients undergoing revascularization, randomized clinical trial have failed to confirm this. This lack of evidence does not support a precise role of viability assessment in the clinical decisionmaking process and therefore myocardial viability should be only one of the several factors considered when choosing revascularization. Further trials to better characterize the role and value of myocardium viability are needed. 


\section{DECLARATIONS}

\section{Authors contribution}

Conception and design: Dimagli A, Benedetto U

Manuscript writing: Dimagli A, Benedetto U

Final approval of manuscript: Dimagli A, Benedetto U

All authors agree to be accountable for all aspects of the work in ensuring that questions related to the accuracy and integrity of any part of the work are appropriately investigated and resolved.

\section{Availability of data and materials}

Not applicable.

\section{Financial support and sponsorship}

None.

\section{Conflict of interests}

Both authors declared that there are no conflicts of interest.

\section{Ethical approval and consent to participate}

Not applicable.

\section{Consent for publication}

Not applicable.

\section{Copyright}

(c) The Author(s) 2021.

\section{REFERENCES}

1. Lippi G, Sanchis-gomar F. Global epidemiology and future trends of heart failure. AME Med J 2020;5:15-15.

2. Salim VS, Alvaro A, Benjamin EJ, et al; American Heart Association Council on Epidemiology and Prevention Statistics Committee and Stroke Statistics Subcommittee. Heart disease and stroke statistics-2020 update: a report from the American Heart Association. Circulation 2020;141:e139-596.

3. Khan MA, Hashim MJ, Mustafa H, et al. Global epidemiology of ischemic heart disease: results from the global burden of disease study. Cureus 2020;12:e9349.

4. Briceno N, Schuster A, Lumley M, Perera D. Ischaemic cardiomyopathy: pathophysiology, assessment and the role of revascularisation. Heart 2016;102:397-406.

5. Allman KC, Shaw LJ, Hachamovitch R, Udelson JE. Myocardial viability testing and impact of revascularization on prognosis in patients with coronary artery disease and left ventricular dysfunction: a meta-analysis. J Am Coll Cardiol 2002;39:1151-8.

6. Schinkel AF, Bax JJ, Poldermans D, Elhendy A, Ferrari R, Rahimtoola SH. Hibernating myocardium: diagnosis and patient outcomes. Curr Probl Cardiol 2007;32:375-410.

7. Camici PG, Prasad SK, Rimoldi OE. Stunning, hibernation, and assessment of myocardial viability. Circulation 2008;117:103-14.

8. Orlandini A, Castellana N, Pascual A, et al. Myocardial viability for decision-making concerning revascularization in patients with left ventricular dysfunction and coronary artery disease: a meta-analysis of non-randomized and randomized studies. Int $J$ Cardiol 2015;182:494-9.

9. Velazquez EJ, Lee KL, Jones RH, et al; STICHES Investigators. Coronary-artery bypass surgery in patients with ischemic cardiomyopathy. N Engl J Med 2016;374:1511-20.

10. Rahimtoola SH. The hibernating myocardium. Am Heart J 1989;117:211-21.

11. Heusch G. The regional myocardial flow-function relationship: a framework for an understanding of acute ischemia, hibernation, stunning and coronary microembolization. 1980. Circ Res 2013;112:1535-7.

12. Vogt AM, Elsässer A, Nef H, Bode C, Kübler W, Schaper J. Increased glycolysis as protective adaptation of energy depleted, degenerating human hibernating myocardium. Mol Cell Biochem 2003;242:101-7.

13. Elsässer A, Schlepper M, Klövekorn WP, et al. Hibernating myocardium: an incomplete adaptation to ischemia. Circulation 1997;96:2920-31.

14. Heusch G. Hibernating myocardium. Physiol Rev 1998;78:1055-85. 
15. Cwajg JM, Cwajg E, Nagueh SF, et al. End-diastolic wall thickness as a predictor of recovery of function in myocardial hibernation: relation to rest-redistribution T1-201 tomography and dobutamine stress echocardiography. J Am Coll Cardiol 2000;35:1152-61.

16. Senior R, Lahiri A. Enhanced detection of myocardial ischemia by stress dobutamine echocardiography utilizing the "biphasic" response of wall thickening during low and high dose dobutamine infusion. J Am Coll Cardiol 1995;26:26-32.

17. Jamiel A, Ebid M, Ahmed AM, Ahmed D, Al-Mallah MH. The role of myocardial viability in contemporary cardiac practice. Heart Fail Rev 2017;22:401-13.

18. Pellikka PA, Nagueh SF, Elhendy AA, Kuehl CA, Sawada SG; American Society of Echocardiography. American Society of Echocardiography recommendations for performance, interpretation, and application of stress echocardiography. J Am Soc Echocardiogr 2007;20:1021-41.

19. Shah BN, Khattar RS, Senior R. The hibernating myocardium: current concepts, diagnostic dilemmas, and clinical challenges in the postSTICH era. Eur Heart J 2013;34:1323-36.

20. Roes SD, Mollema SA, Lamb HJ, van der Wall EE, de Roos A, Bax JJ. Validation of echocardiographic two-dimensional speckle tracking longitudinal strain imaging for viability assessment in patients with chronic ischemic left ventricular dysfunction and comparison with contrast-enhanced magnetic resonance imaging. Am J Cardiol 2009;104:312-7.

21. Kim RJ, Wu E, Rafael A, et al. The use of contrast-enhanced magnetic resonance imaging to identify reversible myocardial dysfunction. N Engl J Med 2000;343:1445-53.

22. Romero J, Xue X, Gonzalez W, Garcia MJ. CMR imaging assessing viability in patients with chronic ventricular dysfunction due to coronary artery disease: a meta-analysis of prospective trials. JACC Cardiovasc Imaging 2012;5:494-508.

23. Chen Y, Zheng X, Jin H, et al. Role of Mmyocardial extracellular volume fraction measured with magnetic resonance imaging in the prediction of left ventricular functional outcome after revascularization of chronic total occlusion of coronary arteries. Korean J Radiol 2019;20:83-93.

24. Kidambi A, Motwani M, Uddin A, et al. Myocardial extracellular volume estimation by CMR predicts functional recovery following acute MI. JACC Cardiovasc Imaging 2017;10:989-99.

25. Stathogiannis K, Mor-Avi V, Rashedi N, Lang RM, Patel AR. Regional myocardial strain by cardiac magnetic resonance feature tracking for detection of scar in ischemic heart disease. Magn Reson Imaging 2020;68:190-6.

26. Baer FM, Theissen P, Schneider CA, et al. Dobutamine magnetic resonance imaging predicts contractile recovery of chronically dysfunctional myocardium after successful revascularization. J Am Coll Cardiol 1998;31:1040-8.

27. Thornhill RE, Prato FS, Wisenberg G. The assessment of myocardial viability: a review of current diagnostic imaging approaches. $J$ Cardiovasc Magn Reson 2002;4:381-410.

28. Wagner A, Mahrholdt H, Holly TA, et al. Contrast-enhanced MRI and routine single photon emission computed tomography (SPECT) perfusion imaging for detection of subendocardial myocardial infarcts: an imaging study. Lancet 2003;361:374-9.

29. Udelson JE, Coleman PS, Metherall J, et al. Predicting recovery of severe regional ventricular dysfunction. Comparison of resting scintigraphy with 201Tl and 99mTc-sestamibi. Circulation 1994;89:2552-61.

30. Madsen S, Dias AH, Lauritsen KM, Bouchelouche K, Tolbod LP, Gormsen LC. Myocardial viability testing by positron emission tomography: basic concepts, mini-review of the literature and experience from a tertiary PET center. Semin Nucl Med 2020;50:248-59.

31. Neumann FJ, Sousa-Uva M, Ahlsson A, et al; ESC Scientific Document Group. 2018 ESC/EACTS Guidelines on myocardial revascularization. Eur Heart $J$ 2019;40:87-165.

32. Beanlands RS, Nichol G, Huszti E, et al; PARR-2 Investigators. F-18-fluorodeoxyglucose positron emission tomography imaging-assisted management of patients with severe left ventricular dysfunction and suspected coronary disease: a randomized, controlled trial (PARR-2). J Am Coll Cardiol 2007;50:2002-12.

33. Mc Ardle B, Shukla T, Nichol G, et al; PARR-2 Investigators. Long-term follow-up of outcomes with F-18-Fluorodeoxyglucose positron emission tomography imaging-assisted management of patients with severe left ventricular dysfunction secondary to coronary disease. Circ Cardiovasc Imaging 2016;9:e004331.

34. Abraham A, Nichol G, Williams KA, et al; PARR 2 Investigators. 18F-FDG PET imaging of myocardial viability in an experienced center with access to $18 \mathrm{~F}-\mathrm{FDG}$ and integration with clinical management teams: the Ottawa-FIVE substudy of the PARR 2 trial. $J$ Nucl Med 2010;51:567-74.

35. Cleland JG, Calvert M, Freemantle N, et al. The heart failure revascularisation trial (HEART). Eur J Heart Fail 2011;13:227-33.

36. Velazquez EJ, Lee KL, Deja MA, et al; STICH Investigators. Coronary-artery bypass surgery in patients with left ventricular dysfunction. N Engl J Med 2011;364:1607-16.

37. Bonow RO, Maurer G, Lee KL, et al. Myocardial viability and survival in ischemic left ventricular dysfunction. $N$ Engl $J$ Med 2011;364:1617-25.

38. Kloner RA. Stunned and hibernating myocardium: where are we nearly 4 decades later? J Am Heart Assoc 2020;9:e015502.

39. O'Meara E, Mielniczuk LM, Wells GA, et al; IMAGE HF investigators. Alternative imaging modalities in ischemic heart failure (AIMIHF) IMAGE HF Project I-A: study protocol for a randomized controlled trial. Trials 2013;14:218. 